\title{
«Was macht das Loch, wenn der Käse alle ist?»
}

Carlo Moll

Vizepräsident VLSS

Korrespondenz:

Dr. med. Carlo Moll

VLSS

Bolligenstrasse 52

CH-3006 Bern
Während Ärztinnen und Ärzte im Kerngeschäft, sei es in Praxen oder Spitälern, «best practice» bieten und dafür eine angemessene, durchaus der Komplexität des Geleisteten entsprechende Entschädigung erwarten, dürfen Kassenmanager, hat man den Eindruck, mit Pflichtprämien und staatlich verordneten Einzahlungen von Bürgerinnen und Bürgern spekulativ hantieren, wie sie wollen [1], ganz im Gegensatz zu Pensionskassen und Lebensversicherern. Dass Verluste an der Börse, etwa von Helsana, ziemlich genau den postulierten 200 Millionen entsprechen, die mit gesenkten Labortarifen eingespart werden sollen, dürfte ein zynischer Zufall sein, entbehrt aber nicht der Ironie und gibt zu denken. Beides wurde auch zufälligerweise am selben Tag kommuniziert.

Sollen Praxen und Spitäler wegen eines im Ganzen höchst spekulativen Spareffektes an den Rand des Laborgroundings gebracht werden, um realisierte Börsenverluste von Versicherern auszugleichen, quasi Spekulation gegen Spekulation? Wohl kaum so direkt, hoffen wir alle. Dennoch wäre dies eine interessante Idee, Verluste auf dem Buckel der Ärzteschaft zu kompensieren, während Gewinne andere Verteilschlüssel aufweisen.

Die Börsenverluste in den Teppichetagen von Gesundheitskassen werden subtil behandelt und in der Tagespresse kaum hinterfragt. Niemand wagt es, diesen halböffentlichen/halbprivaten «Service Public» härter anzufassen. Während wir Ärzte unter diagnostischer und therapeutischer Dauerbeobachtung stehen und Warnbriefe erhalten, wenn wir zu viele polymorbide Patienten zu Hause besuchen und in der Praxis oder im Spital betreuen, erfreuen sich Kassenmanager im Anlagegeschäft der Narrenfreiheit und müssen niemandem Rechenschaft ablegen. Dies sollte sich dringend ändern, denn es handelt sich letztlich um Prämiengelder potentieller Patienten und nicht um Anlageoptionen von Private-BankingKunden.

Solange jedoch Kassenlobbyisten unter Parlamentmitgliedern offensichtliche Interessenkonflikte bagatellisieren, sich selbst aus der Schusslinie nehmen und in gesundheitspolitischen Gremien nicht frei sind, solange wird der offene Blick auf ein faires, betriebs- und volkswirtschaftlich profitables Gesundheitswesen für alle (!) Be- teiligten in unserem Land getrübt. Man kann sich das System nicht einfach der eigenen Interessenlage entsprechend zurechtlegen. Die steigende Zahl von Köchen, vor allem aus der wachsenden Beraterindustrie, macht das Menu weder schmackhafter noch günstiger. Es wurde in den letzten Monaten und Jahren viel am Ärzteimage herumgeschraubt - zu viel, möchte man sagen. Unser Beruf wird, wo wir ihn am nötigsten haben, zunehmend in die Unattraktivität manövriert. Es ist nicht zuletzt eine politische Fehlleistung, wenn junge Ärztinnen und Ärzte lieber Spezialisten in der Stadt als Hausärzte in ländlichen Gegenden werden wollen. Dies ist kein Eingeständnis einer gespaltenen Ärzteschaft, wie man uns gerne einreden möchte, sondern die Erkenntnis, dass das alte «divide et impera» glühende Anhänger auf höchster Stufe hat. Die natürliche Heterogenität unserer ärztlichen Berufslandschaft wird noch so gerne instrumentalisiert, indem uns Uneinigkeit und interne Führungsschwäche vorgeworfen wird. Stattdessen fehlen kreative und mutige Ideen oder sie werden, wenn sie von uns kommen, einfach ignoriert. Das gebotene Flickwerkszenario hat durchaus Mobbingcharakter und geht bis zur Diskussions- oder Informationsverweigerung. Ein grober Fehler, gerade in der heutigen Zeit, wo die Ärzteschaft in grundsätzlichen Fragen noch nie so geschlossen war. Inkompetenz, Faktenignoranz, Erfolgszwang und Selbstüberschätzung sind keine guten Partner. Darauf würden wir nicht eine einzige Behandlung stützen. Das gilt gerade jetzt bei der Revision der Analysenliste. Parteien von links bis rechts haben das inzwischen realisiert. Die Retourkutsche von Bundesrat Couchepin in der NZZ [2] war etwas zu sachfremd. Sie war weit entfernt von staatsmännischer Souveränität und funktioniert so nicht. Was nicht wahr ist, kann nicht funktionieren.

\section{Literatur}

1 Rizzi E. Anlagestrategien Krankenkassen: Der weisse Fleck soll weg. Schweizer Versicherung. 2009:21(3):22-3.

2 Bühler S, Häfliger M. «Ich scheine mich als Feindbild zu eignen». Interview mit Bundesrat Pascal Couchepin. NZZ am Sonntag,

22. Februar 2009, S. 10-1. 